
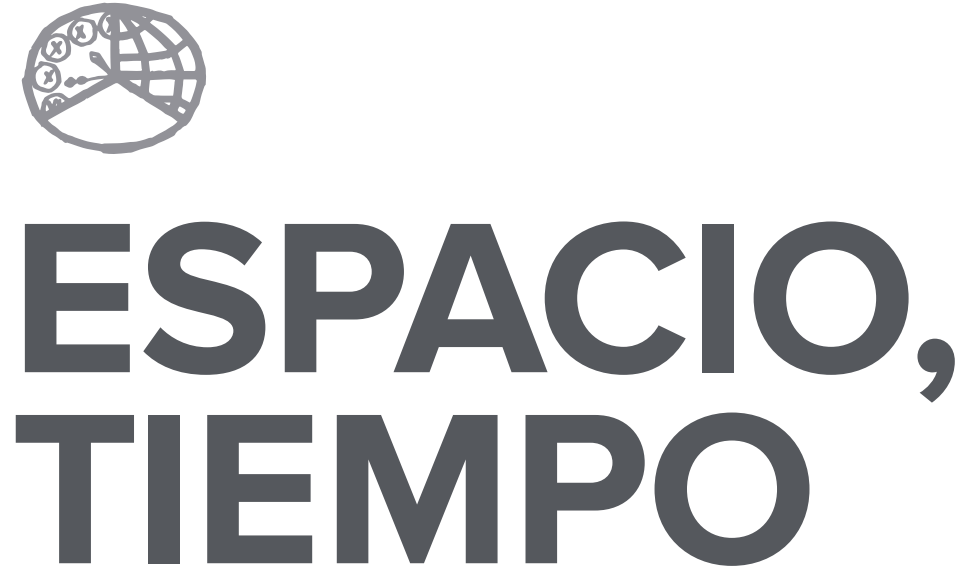

AÑO 2019

ISSN 0214-9745

E-ISSN 2340-1362
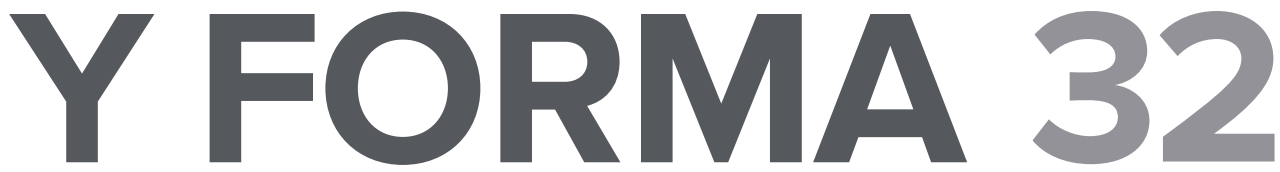

SERIE III HISTORIA MEDIEVAL

REVISTA DE LA FACULTAD DE GEOGRAFÍA E HISTORIA

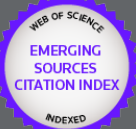



NOTAS DE FILOLOGÍA CASTELLANA MEDIEVAL •

NOTES OF MEDIEVAL CASTILIAN PHILOLOGY 



\title{
NOTAS BIBLIOGRÁFICO-CRÍTICAS \\ DE FILOLOGÍA CASTELLANA MEDIEVAL
}

\section{CRITICAL BIBLIOGRAPHICAL NOTES ON MEDIEVAL CASTILIAN PHILOLOGY}

\author{
Francisco Abad Nebot ${ }^{1}$ \\ DOI: http://dx.doi.org/10.5944/etfiii.32.2019.23961
}

A mis alumnos (1970-2019)

\section{Resumen}

Los presentes párrafos indican fuentes primarias o secundarias acerca de la lengua y la literatura castellanas medievales; se analizan las primeras, y se orienta acerca de las segundas. Se trata de mantener un punto de vista específicamente filológico y atento, por lo tanto, a lengua, literatura e historia.

\section{Palabras clave}

Pedro Abad; dialecto aragonés; dialecto riojano; Menéndez Pidal; José Hernando Pérez.

\section{Abstract}

The following study identifies primary and secondary sources of medieval Castilian language and literature: primary sources will be analysed, while secondary sources will merely be commented for future research. This article adopts a strictly philological approach and hence will focus on language, literature and history.

Keywords

Pedro Abad; Aragonese Dialect; Riojan Dialect; Menéndez Pidal; José Hernando Pérez. 
NO EXISTE, que sepamos, una exposición de conjunto acerca del idioma castellano medieval: debe acudirse a las Historias generales de la lengua; sí hay en cambio iniciaciones a la literatura coetánea, al menos una: la de Francisco López Estrada Introducción a la literatura medieval española ( $5^{\mathrm{a}}$ ed., Gredos). Según se ve, esta obra ha pasado por varias ediciones de texto.diferenciado; por ejemplo la que se encontraba en el mercado a mediados de los pasados años sesenta planteaba a los estudiantes alguna dificultad debido a alguna falta de claridad expositiva que encontraban en ella. Como era de esperar, el autor dedica capítulos sucesivos a las canciones mozárabes; a la épica; a las obras 'clericales'; a la prosa, Alfonso X y don Juan Manuel; al romancero y el teatro; a la poesía cancioneril; al Cuatrocientos y sus géneros y autores; ... Sin duda esta quinta edición a la que aludimos resulta la más lograda, y presta útiles servicios para el principiante y acaso para el menos principiante.

López Estrada llega a concluir que

el dialecto castellano comienza a afirmarse como lengua establecida por el uso escrito literario en la prosa con la actividad de Alfonso $X$; $y$ en el verso asegura su existencia escrita en las obras de la clerecía. [...] La lengua literaria se enriquece progresivamente y asimila los influjos de lo que son las modas renovadoras: árabe, provenzal, francés e italiano.

Desde luego para lo árabe y lo provenzal hoy en día resultan fundamentales los escritos respectivos de Federico Corriente y de Martín de Riquer, sólidos los de uno y otro.

En cuanto al castellano y los otros dialectos medievales ya hemos dicho que deben seguirse en las dos obras principales que remiten a nuestra historia de la lengua: nos referimos a la de Menéndez Pidal (2005, ed. póstuma) y a la de Rafael Lapesa ( $9^{\mathrm{a}}$ ed. y última,I98I). El texto pidalino llega sólo hasta I68o, y ello por varios motivos: asuntos fundamentales en referencia al idioma habían evolucionado y se habían establecido ya -don Ramón interpretaba que la pronunciación moderna se había alcanzado ya en alguna de sus manifestaciones h. I592: el siglo XVIII pertenecía a un pasado extranjerizante, lo que en general lo descalificaba en la estimación convencional, y para la misma mentalidad establecida, el XIX era rechazado por liberal; a un hombre del Ochocientos como Pidal ese XVIIl y no digamos el XIX resultaban muy próximos; etc. No obstante, don Ramón pretendió llegar -según sus apuntes personales- hasta el «surrealismo», aunque esto no pasó de un deseo programático. De la presente obra a la que aludimos (R. M. P., Historia de la lengua española) importan las páginas que van desde la 253 hasta el final del libro. Del texto de igual título de Lapesa han de verse para lo medieval

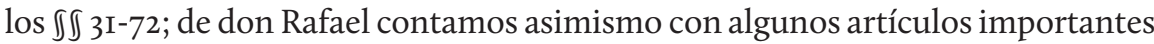
de los años últimos de su vida y que andan dispersos.

Tanto uno como otro de los dos autores (Menéndez Pidal, Lapesa) incluyen en su tratamiento el del idioma hablado común -hasta donde es posible inducirloy la lengua artística literaria; Dámaso Alonso -al igual que Lapesa de la escuela inmediata pidalina- llevó a cabo también análisis del estilo literario de más de un 
escritor (Góngora, etc.). Hoy suele prescindirse del examen de la lengua artística al estudiar la trayectoria del idioma, con lo que se pierde adecuación empírica: ya decía Menéndez Pelayo que es más cómodo saber menos que saber más.

$$
* * *
$$

La pérdida de la $f$ - en los textos antiguos castellanos empieza a documentarse desde el siglo IX por influencia de la lengua vasca o lenguas afines; esto nos retrotrae en efecto a la lengua vasca. Existe una conferencia de Menéndez Pidal de I923 («Influjo del elemento vasco en la lengua española»), incorporada con otros escritos a su volumen En torno a la lengua vasca (Austral $n^{\circ}$ I30I); cfr. asimismo varios capítulos de su volumen importante Toponimia prerrománica hispana, especialmente los que aparecen en primer lugar y los ordenados como noveno, décimo y undécimo -los capítulos no van numerados-.

Por supuesto para la protolengua peninsular la obra imprescindible es el texto magistral -magistral en todo el conjunto de los estudios románicos- de don Ramón Menéndez Pidal Orígenes del español (versión definitiva en I950).

Un texto que en lo literario tiene algo de paralelo con Orígenes... es el asimismo pidalino que en la edición definitiva de Diego Catalán se rotula Reliquias de la poesía épica española (I980). En efecto, se trata en ambos textos de recuperar e ilustrar las reliquias del más antiguo protorromance y de la épica española, respectivamente. Estamos -diríamos- ante una filología arqueológica; Enrique Moreno Báez - a quien ahora citamos de memoria- habló en efecto de don Ramón en tanto arqueólogo a su manera. Nunca lo hemos dicho, pero creemos que es así: «Orígenes...»y «Reliquias» resultan obras estrictamente paralelas y coherentes entre sí dentro de lo filológico.

No acostumbra a tenerse en cuenta el bello escrito asimismo pidalino «Repoblación y tradición en la cuenca del Duero», integrado en la «Introducción» puesta por don Ramón al vol. I de la Enciclopedia Lingüística Hispánica (1960); para estos asuntos vid. su Historia, caps. III y IV de la Parte Tercera, incluso los capítulos inmediatamente posteriores a estos.

Las Glosas Emilianenses «quieren ser transcripción de la lengua vulgar», y tienen fecha discutida, pero quizá debe seguir estimándoselas del siglo X -de hacia 950- (vid. en la Historia de la lengua de Pidal el cap. V de su Parte Tercera). Por su lado, Fernando González Ollé es autor de una muy amplia monografía: «Vascones y vascuence. Historia (para romanistas) de una relación», accesible por medios informáticos.

En la presente temática son numerosos los escritos de Claudio García Turza, y entre ellos: «San Millán de la Cogolla y su influencia en la historia de la lengua española»; «La datación y procedencia de las Glosas Emilianenses y Silenses: anotaciones críticas a los nuevos planteamientos» (con Javier García Turza); «La Glosa 89 del EM. 6o, 'el primer vagido del español' »; «Estudio preliminar» -en 
colaboración- a Glosas Emilianenses, Gobierno de La Rioja, I992; etc. Todos estos escritos resultan accesibles con el buscador Google.

A su vez son, sin embargo, muy ligeros y casi intrascendentes los comentarios de Alonso Zamora Vicente, «Significación de las Glosas Emilianenses», asimismo accesible informáticamente; en cambio, hay datos eruditos en el amplio «Prólogo» del abad de Silos Luciano Serrano al Cartulario de San Millán de la Cogolla (Madrid, JAE, I930).

De manera general no cabe olvidar la Antología de poetas líricos castellanos del gran Menéndez Pelayo, de momento en su tomo I. El asunto de las llamadas canciones andalusíes ha despertado tradicionalmente el interés de don Ramón y sus discípulos: Dámaso Alonso, Álvaro Galmés, etc., y el de Emilio García Gómez. Muy otra en sus resultados es la investigación que en estos años últimos lleva a cabo Federico Corriente. Los escritos pertinentes pidalinos tienen ahora una edición conjunta: R. M.P., Estudios sobre lírica medieval (Madrid, CECE, MMXIV), texto de manejo cómodo y útil. Y Álvaro Galmés ha realizado una magna recopilación de aportaciones pidalinas: Islam y Cristiandad, Univ. de Málaga, 200I, dos volúmenes.

Menéndez Pidal editó asimismo unos Documentos lingüísticos de España. Reino de Castilla de entre io44 y I492. Se trata de una fuente a la que hay que atender inexcusablemente.

A tiempos de Alfonso Vl y a su persona se refirió Menéndez Pidal en dos escritos respectivos, a saber: «Adefonsus imperator toletanus, magnificus triumphatur», (Austral, $\mathrm{n}^{\mathrm{o}}$ I72) y «'Galiene la belle' y los palacios de Galiana en Toledo» (Austral, $\mathrm{n}^{\mathrm{O}}$ I90)- ambos estudios habían aparecido ya en su Historia y Epopeya (JAE, I934); de la Historia de la lengua...vid. pp. 409-4I8, y en general, los caps. IX y X. En nuestros días se cuenta con magníficas monografías acerca de este Alfonso (I065-IIo9), de Carlos Estepa y de José María Mínguez.

En general, Lapesa, Historia..., cap. VIl.

Sobre el dialecto medieval riojano se encuentra la documentación de Valbanera (ed. del paleógrafo y Rector compostelano Manuel Lucas Álvarez, EEMCA, IV, I95I, pp. 45I-547; estudio de M. Alvar en AFA, IV, I952). Más en general, el riojano está analizado por el mismo $\mathrm{M}$. Alvar en su volumen reordenado en la $2^{\mathrm{a}}$ ed. de Gredos, El dialecto riojano, y cfr. del propio autor el artículo «De las Glosas Emilianenses a Gonzalo de Berceo», RFE, enero-junio I989, pp. 5-38, acaso algo difuso. En la Historia pidalina, vid. el cap. Il de la Parte Cuarta.

Claudio García Turza es también especialista en este asunto -acaso el mejor especialista-; vid. su buena edición de los Milagros de Berceo (I984), y el libro muy oportuno con J. García Turza, Una nueva visión de la lengua de Berceo a la luz de la documentación emilianense del siglo XIII, Universidad de La Rioja, I996; esta obra es de necesaria consulta. Escrito clásico es el de G. Tilander «La terminación -I por 
-E en los poemas de Gonzalo de Berceo», RFE, XXIV, I937, pp. I-Io; ahora escribe por igual sobre el dialecto riojano un antiguo doctorado del prof. García Turza. Importa el punto de vista -discrepante con buenas razones del de J. J. Bustos- del prof. Olegario García de la Fuente, El latín bíblico y el español medieval hasta el 1300. I. Gonzalo de Berceo, IER, Logroño, $2^{\mathrm{a}}$ ed., I992. Asimismo vid. Emilio Montero, Gonzalo de Berceo y el 'Libro de Alexandre', Universidad de Santiago de Compostela, I989.

Hemos leído y analizado por nuestra cuenta el Becerro de Valbanera: he aquí algunos rasgos de su lengua (para entender plenamente esto se precisan algunos conocimientos de gramática histórica castellana):

- en cuanto a la diptongación, aparecen las formas Guttiar (p. 513); lombiello (p. 498); lenneco (p. 47I); meirino (p. 530).

- por lo que se refiere al consonantismo, encontramos respectivamente Ortiz (p. 494); in lano 'plano' (p. 563); Fonte Putia (p. 409); Latesma -ultracorrección- (p. 555); lombo (p. 553); anolio (p. 557); Ual Ota (p. 472); etc.

- en morfología, lo -artículo- (p. 488); lures (p. 529).

- vocabulario: las formas vascas Eita (p. 508); Anderazo (p. 465).

Lo anterior no es más que una muestra; mayor detalle en el artículo mencionado de Alvar del Archivo de Filología Aragonesa.

$$
* * *
$$

La época de la segunda mitad del siglo XIl y de inicios del XIII puede denominarse como «época de Alfonso VIII».

Desde luego hay que tener presentes las pp. 407-483 de la Historia de la lengua... de Menéndez Pidal; en el texto análogo de Lapesa, vid. su cap. VIIl. Hay un volumen de M. Ariza, La lengua del siglo XII, que llama la atención por la renuncia que hace el autor a ocuparse del Cid y de los problemas que plantea; en la p. 343 el propio autor menciona cinco textos suyos: en el segundo y el tercero alude al llamado sistema gráfico alfonsí, a la -e, etc.

El hablar de Toledo queda aludido en el capítulo de Jean-Pierre Molénat en el bello libro editado por Louis Cardaillac, Toledo siglos XII-XIII.

«Para algunos, el primer documento plenamente romance es la carta-puebla de Villa Algariva de II9I»; así dice muy prudentemente Pedro Sánchez-Prieto, quien añade que hacer afirmaciones de esta clase supone «pisar terreno resbaladizo». Ángel Gómez Moreno, en cambio, se ha mostrado bastante partidario de la tal prelación .

Los Fueros de Avilés y de Madrid han sido estudiados -como bien se sabe- por Rafael Lapesa; una conferencia sobre el segundo de ellos a cargo de José Fradejas resulta penosa en algún momento, como texto de un profesor que era ajeno a los estudios idiomáticos. 
No debe quedar inadvertido -y lo ha quedado- el escrito de José Hernando Pérez sobre el Cid; es un estudioso que antes se había ocupado de otros textos medievales, del Alexandre, y del Fernán González.

Obra de importancia que ha pasado -según decimos- casi inadvertida es esta del autor: Pedro Abad - Mair Yahya Ben Gâlib. El cantor del Mio Cid. De hecho nada más la hemos visto mencionada por el enorme arabista Federico Corriente, quien ha subrayado la buena argumentación que hace el autor; el texto no se encuentra en la Biblioteca Nacional.

La obra posee mucha profusión de detalle, y traza así cuadros de acontecimientos, $\mathrm{y}$, por supuesto, tiene además y fundamentalmente un centro del estudio que se hace. La conclusión o tesis defendida es la anunciada y enunciada en el título, o sea, la identidad de quién es el autor del Poema.

Por igual esta monografía repite otras atribuciones que su autor ya tenía hechas, y en concreto la de la autoría del Libro de Alexandre y del Poema de Fernán González a favor del canciller de Castilla Diego García (reinados de Alfonso VIII y de Enrique I). El canciller y Pedro Abad «contribuyeron a que el idioma castellano levantara el vuelo, se hiciera robusto y bello y se extendiera».

Pedro Abad era un presbítero, «capellán de milicia, mozárabe, poseedor de dos nombres, dos idiomas y dos culturas, [...] seguidor del emperador Alfonso VII en las expediciones guerreras por el Sur de la Península». Se trata, pues, de «un presbítero de la mozarabía y de las milicias de Toledo [...]. Oficiaba en la liturgia para militares de campaña; conocedor por tanto de las costumbres de los luchadores, con los cuales compartía penas, alegrías y entusiasmos. [...] El Mio Cid sería, pues, la obra de un poeta de gesta experimentado, hombre de muchas letras y presbítero en campaña».

Igualmente, y en la hipótesis de José Hernando, «probablemente, ya en II50, Pedro Abad [que alcanzaría unos 85 años] componía versos sobre la figura legendaria del héroe burgalés y trazaba en su mente las líneas guía para una obra que iba a componer». Resume y subraya de nuevo Hernando cómo «nuestro Ben Gâlib era de etnia mozárabe, de dos culturas y dos idiomas, y además de cristiano, era un presbítero dedicado a la milicia y buen conocedor del latín. Rodeado de gentes ilustres y de francos intelectuales, era entendido en la épica».

En definitiva, estamos ante un Pedro Abad de notoria cultura literaria, y que verosímilmente se movió entre los expertos en Derecho de finales del siglo XII. Pedro Abad, en I203, informa en fin José Hernando, extendió un documento en el que «añadió a su nombre el apelativo de poeta, indicio evidente de que era por entonces reconocido como tal»; a saber, «precisamente estos años, es decir, de tres a cinco antes de I207, son los de la composición de la obra». Dadas las fechas, no penetró en el texto del Poema el espíritu de cruzada de los meses previos a las Navas de Tolosa, como ha defendido J. Fradejas.

Queda dicho cómo la presente monografía de don José Hernando Pérez registra gran número de acontecimientos seguidos con buena y mucha erudición, 
y que va apuntalando asimismo una idea central: el mozárabe Pedro Abad es «el cantor del Mio Cid».

Los escritos acerca del Cid son muy numerosos; véase por ej. el volumen de conjunto del propio Menéndez Pidal En torno al 'Poema del Cid'-hay reedición póstuma por la que citan algunos profesores, que parecen desconocer que el libro viene de atrás-. En el otro título pidalino La epopeya castellana a través de la literatura española (1945), se encuentra -más allá de lo que anuncia el título-, una especie de panorama de conjunto acerca de los problemas de la épica castellana; la obra fue reseñada por Lapesa en la NRFH.

En el volumen colectivo Los orígenes del español y los grandes textos medievales. Mio Cid, Buen Amor y Celestina, véase el escrito del excelente investigador Francisco J. Hernández, «Acercamiento a los orígenes del español escrito». En otro volumen colectivo, Lenguas, reinos y dialectos en la Edad Media ibérica, deben verse la aportación de Pedro Sánchez-Prieto y otras más.

En fin, la Razón de amor o Siesta de Abril ha quedado aludida por Menéndez Pidal, quien considera este poema en tanto perteneciente al período final del español primitivo» (Historia... pp. 479-48i; Poesía juglaresca, $7^{\mathrm{a}}$ ed., pp. I38-I39).

En referencia a la clerecía recuérdense estas palabras de Menéndez Pelayo: «Abre nueva era en la historia del arte castellano la aparición de la primera escuela de poesía erudita, escuela cuyo desarrollo comprende siglo y medio, [...] hasta mediados del XIV» (puede orientar I. Uría, Panorama crítico del mester de clerecía). A lo dicho sobre el riojano súmese Joaquín Artiles, quien hace indicaciones de lengua y estilo en sus dos libros Los recursos literarios de Berceo y -en otra temática- El «Libro de Apolonio», poema español del siglo XIII. Antonio Ubieto -que ya llamó la atención tempranamente sobre la cronología del Cid, trata de la cronología de obras de clerecía (aunque él hable de épica -sic-) en el artículo «Valoración de la épica en el contexto histórico español», con dataciones no siempre verosímiles -escrito accesible mediante Google-. Luego, en el devenir del mismo Doscientos cabe llamar la atención sobre el «Fuero general de Navarra»; fragmentos escogidos del texto pueden encontrase en la 'Crestomatía' pidalina y en los 'Textos medievales' de F. González Ollé' . Para Alfonso X, etc., se encuentran ahora referencias -después de los clásicos escritos de Antono Badía, etc.- en el trabajo de Juan Camilo Conde Sociolingüistica histórica, Madrid, Gredos, 2007.

A mediados de ese Doscientos fecha Deyermond el planto «jAy, Iherusalem!» (es un poco más tardío, según E. Asensio): ambos críticos se han ocupado del texto, que puede verse en M. Alvar, ed., Antigua poesía española lírica y narrativa, México, Porrúa, I98I, pp. I79-I86. A propósito del presente texto nuestro condiscípulo J. Romera ha dicho que «las grafías que representan el sistema consonántico fueron establecidas por el castellano drecho de Alfonso X»; no creemos 
nosotros que la lexía alfonsí signifique eso, pues alude más bien a una elocución semánticamente adecuada en sus designaciones.

La denominada tradicionalmente «La herencia alfonsí» cabe ser llamada asimismo -proponemos- «la época de los Fueros leoneses», en relación a los editados por Federico de Onís y Américo Castro. Cfr. el I 64 de la Historia.. .de Lapesa, quien menciona textos del momento en su n. I6, a los que por igual remitimos nosotros. También M. Alvar, El fuero de Salamanca, Univ. de Granada, I968, una precisa monografía.

Tenemos leído este Fuero y anotamos ahora algunos de sus rasgos de lengua, castellanos o dialectales leoneses; según queda ya dicho, para entender plenamente esto se precisan algunos conocimientos de gramática histórica. Tenemos, a saber (se cita por la pág. de la edición de Federico de Onís en Fueros leoneses. I, Madrid, JAE, I9I6):

- en cuanto al vocalismo: aparecen las formas 'segurancia' (29); 'morto' y 'soldos', sin diptongación (pág. 77); 'heredade’ (8I) , con vocal final conservada; 'cuchiello' (95); 'escriuan' (I20) y también 'escriuano' (I22).

- sobre las consonantes: casos como 'conceyo' (80); 'iulgaren' (82);'oueya' (Iо3); 'robre' (Iо9); 'peche' (III); 'furto' (II9); 'palonba' (I28) o 'paloma' (I60).

- fórmulas morfológicas 'le lo' <illi illu, o 'le la' <illi illa (82; 95); la asimilación 'eno' (95).

- artículo más posesivo: 'el my cuerpo' (II2).

- el vocabulario incluye el arabismo 'nubda' (I48), que era el 'servicio para protección del ganado'.

Según se puede comprobar y sintetiza Manuel Alvar, faltan en el «Fuero de Salamanca» sucesivos rasgos específicamente leoneses, mientras en otras ocasiones «el castellanismo es evidente» ( $\int 25$ de la obra cit., y cfr. $\left.\int 27\right)$. Este mismo investigador escribe también: «El leonesismo es innegable, pero aparece difuso a lo largo de todo el texto; las formas dialectales alternan con las castellanas, y con frecuencia, son estas las que predominan» $(\sqrt{4} 48)$.

Luego vendrán don Juan Manuel y el que sabemos hoy que era arcipreste real de Hita Juan Ruiz -con análisis (que ahora recordemos) de Menéndez Pidal, de Corominas y de M. Alvar; de este último autor cfr. su Miscelánea de estudios medievales, $I$, , pp. 30I-324 (en el vol II de esta Miscelánea aparecen algunos datos sobre el siglo XV) -un epígrafe acerca de «La lengua del siglo XIV» se halla en la Historia mínima de la lengua española de don Luis Fernando Lara, El Colegio de México, 2015 (reimpr.) ; vendrán Juan de Mena y Santillana -estudiados de manera respectiva por $\mathrm{M}^{\mathrm{a}}$. Rosa Lida -eruditísimamente- y por Lapesa, autor este último 
que también se ha ocupado de Juan de Lucena y de Gómez Manrique, e interesado siempre en el Cuatrocientos y en su huella y continuidad en Garcilaso; ...

Francisco Marcos ha mantenido -lo citamos de memoria- que la lengua del siglo XV y la del Quinientos son lenguas distintas: no lo creemos nosotros así, y de hecho no hemos visto autor alguno que se haya hecho eco de la idea y la haya aceptado.

$$
\text { *** }
$$

Entre nosotros asistimos a una visible quiebra de los estudios filológicos. No se leen las obras, sino que se acude para documentar los hechos al CORDE, que es un cómodo inventario de ejemplos; se extraen datos mediante internet y se transcriben en papel como si fuesen propios, lo cual es una impostura, como es impostura tomarle datos o enunciados a Lapesa sin reconorle la autoría; se trata acerca de asuntos laterales como «literatura y ecología», cuando -según reclamó E. Moreno Báez hace más de medio siglo- no se han estudiado a fondo la lengua y estilo, y el pensamiento, de un Quevedo; se prescinde de los textos de Menéndez Pidal, vigentes en buena parte; ...

A la excelsa escuela filológica española pidalina le ha sucedido casi un vacío, lo que no quiere decir que en enfoques lingüísticos no filológicos no se hayan logrado páginas sólidas y brillantes (a veces, sin embargo, la carencia -al parecer- de conocimientos filológicos, ha ensombrecido distintas aportaciones individuales y colectivas), etc.

Se conoce a profesores oficiales de literatura que apenas leen literatura (y no somos los únicos que lo testificamos y decimos), o que se desprenden de obras muy pertinentes y las donan a Bibliotecas porque se diría que no saben estimarlas, ... Nosotros hemos visto en bibliotecas -a lo largo de los años- algunas joyitas por la edición, por el contenido, o por ambas cosas, que un catedrático con verdadera vocación nunca dejaría salir de su casa. 


\section{BIBLIOGRAFÍA}

Alvar, Manuel: El dialecto riojano. Madrid, Gredos, 1976 ( $2^{\mathrm{a}}$ ed.).

Alvar, Manuel: El fuero de Salamanca. Univ. de Granada, I968.

Alvar, Manuel, ed.,: Antigua poesía española lírica y narrativa. México, Porrúa, I98I.

Alvar, Manuel: Miscelánea de estudios medievales, I y II. Zaragoza, Diputación General de Aragón, I990.

ARTiles, Joaquín: Los recursos literarios de Berceo , segunda ed. Madrid, Gredos, I968.

ARTILES, Joaquín: El «Libro de Apolonio», poema español del sigo XIII. Madrid, Gredos, I976.

CARDAILlaC, Louis: Toledo siglos XII-XIII. Madrid, Alianza, I992.

CONDE., Juan Camilo: Sociolingüística histórica. Madrid, Gredos, 2007.

GARCíA DE LAFUENTE, Olegario: El latín bíblico y el español medieval hasta el I30o. I. Gonzalo de Berceo. IER, Logroño, $2^{\mathrm{a}}$ ed., I992.

García Turza, Claudio y Javier: Una nueva visión de la lengua de Berceo a la luz de la documentación emilianense del siglo XIII. Universidad de La Rioja, I996.

Hernando Pérez, José: Pedro Abad - Mair Yahya Ben Gâlib. El cantor del Mio Cid. Burgos, Facultad de Teología del Norte de España, 2or4.

LAPESA, Rafael: Historia de la lengua española. Madrid, Gredos, $9^{\mathrm{a}}$ ed., I98I.

LARA, Luis Fernando: Historia mínima de la lengua española. El Colegio de México, 2015 (reimpr.)

LóPEZ EsTRAdA, Francisco: Introducción a la literatura medieval española (5 ${ }^{\mathrm{a}}$ ed.). Madrid, Gredos, I983.

LuCAS Álvarez, Manuel, ed., «Libro Becerro de Valbanera», EEMCA, IV, I95I, pp. 45I-547.

Menéndez PIDAL, Ramón: Historia y Epopeya. Madrid, JAE, I934.

MENÉNDEZ PIDAL, Ramón: La epopeya castellana a través de la literatura española. Buenos Aires, Espasa-Calpe Argentina, I946.

MenÉndez Pidal, Ramón: Orígenes del español. Ed. definitiva, I950, Madrid, Espasa-Calpe.

MenÉndez Pidal, Ramón: Toponimia prerrománica hispana. Madrid, Gredos, I952.

MEnÉndez PidAL, Ramón: Poesía juglaresca y orígenes de las literaturas románicas. Madrid, IEP, I957, 6 a ed.

MenÉndez PidAl, Ramón: En torno a la lengua vasca. Buenos Aires, Espasa-Calpe Argentina («Austral», $\mathrm{n}^{\circ}$ I30I), I962.

Menéndez Pidal, Ramón: En torno al 'Poema del Cid'. Barcelona, EDHASA, I963 -hay reedición póstuma por la que citan algunos profesores, que parecen desconocer que el libro viene de atrás-.

MenÉndez PidAl, Ramón: Reliquias de la poesía épica española. Madrid, Seminario Menéndez Pidal, I980 -ed. de D. Catalán-.

MenÉndez Pidal, Ramón: Islam y Cristiandad, Univ. de Málaga, 20oI, dos volúmenes.

MenÉndez PidAL, Ramón: Historia de la lengua española. Madrid, RAE -Fundación Menéndez Pidal, 2005.

MenÉndez PIDAL, Ramón: Estudios sobre lírica medieval. Madrid, CECE, MMXIV.

Montero, Emilio: Gonzalo de Berceo y el 'Libro de Alexandre'. Universidad de Santiago de Compostela, I989.

SÁNchez Prieto, Pedro: «El romance en los documentos de la catedral de Toledo (II7II252)», RFE, 87 (2007), pp. I3I-I78.

Serrano, Luciano: Cartulario de San Millán de la Cogolla. Madrid, JAE, I930.

URíA, Isabel: Panorama crítico del mester de clerecía. Madrid, Castalia, 2000.

VV.AA.: Fueros leoneses. I. Madrid, JAE, I9I6. 
NOTAS BIBLIOGRÁFICO-CRÍTICAS DE FILOLOGÍA CASTELLANA MEDIEVAL

VV.AA., Enciclopedia Lingüística Hispánica .Madrid, CSIC., I960.

VV. AA. Los orígenes del español y los grandes textos medievales. Mio Cid, Buen Amor y Celestina. Madrid, CSIC, $200 \mathrm{I}$.

VV.AA. : Lenguas, reinos y dialectos en la Edad Media ibérica. Madrid, Iberoamericana, 2008. 

Calidad de Revistas

Científicas Españolas

FECYT |
AÑO 2019

ISSN: 0214-9745

E-ISSN 2340-1362

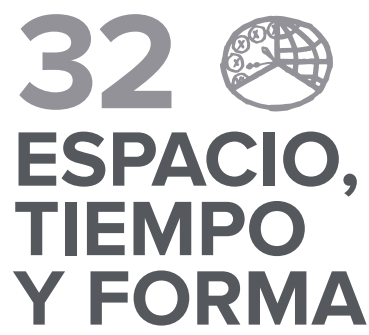

SERIE III HISTORIA MEDIEVAL

REVISTA DE LA FACULTAD DE GEOGRAFÍA E HISTORIA

\section{Artículos · Articles}

Joaquín Aparici Martí \& Concepción VillanueVa Morte Deslindes y amojonamientos medievales en las serranías de Gúdar-Maestrazgo: un acercamiento al patrimonio rural y a la didáctica del territorio

\section{CARLOS BARQuero GoÑ}

Los hospitalarios y los monasterios en la Corona de Castilla durante los siglos XII y XIII

\section{Rocío BELLO GAY}

Representación política, oficios concejiles y acumulación económica en las aldeas abulenses en la Baja Edad Media: algunos apuntes acerca de la caracterización de las Ilamadas elites rurales (1474-1504)

105 Albert Cassanyes Roig Edad Media

La iglesia de Mallorca y la redención de cautivos en la Baja

133 Julián Clemente Ramos

Una dehesa por dentro: Castilrubio (1290-c. 1545). Paisaje, explotación y usurpación de términos

161 Francisco josé Díaz Marcilla

Las relaciones sociales dentro del Cancionero de Juan Alfonso de Baena (siglo XV). Redes y mentalidades

187 GUILLERMO FERnÁNDEZ ORTIZ

El archivo del monasterio cisterciense de Nuestra Señora de Belmonte (Asturias, España) en vísperas de la Reforma (1560)

\section{IVÁN GARCíA IZQUIERDO}

El linaje de Aza durante los siglos XIII y XIV: declive y resurgimiento

267 JAVier López RÍder

Migraciones rurales en el paisaje meridional del Reino de Córdoba en el tránsito de la Edad Media a la Moderna

303 Jesús Rodríguez Morales \& DAVID GonzÁlez Agudo
Los caminos de la repoblación segoviana en la Transierra entre los siglos XIII y XV a partir del Privilegio de las Alberguerías de 1273

337 Jonatan Romero Pérez el siglo XIV
Estructuras militares y logísticas en la Corona de Castilla durante
379 VICENT ROYO PÉREZ

Árbitros y mediadores en el mundo rural valenciano durante la Baja Edad Media: Els Ports y El Maestrat (s. XIII-XIV)

Xosé M. SÁNCHEZ SÁNCHEZ

Aproximación al concejo de la ciudad de Santiago de Compostela y su configuración entre los siglos XIII-XV. Un poder urbano en el señorío episcopal

\subsubsection{Fernando Serrano Larráyoz \& Manuel Francisco CARRILlo Rodríguez}

Nueva perspectiva acerca de las enfermedades de Enrique IV de Castilla: el recetario del doctor Gómez García de Salamanca

\subsection{Néstor Vigil Montes}

«Tractados de pazes, aliança e concordia entre as duas coroas de Portugal e Inglaterra», un cartulario realizado a comienzos del siglo XV para consolidar el Tratado de Windsor entre los reinos de Inglaterra y Portugal (1386), la alianza permanente más prolongada de la historia

\section{Notas de Filología castellana medieval · Notes of Medieval Castilian Philology}

(9) 1 Francisco Abad Nebot

Notas bibliográfico-críticas de Filología castellana medieval

\section{Libros · Books}

515 Arsuaga Laborde, Diego, Pedro Fernández de Velasco, primer conde de Haro. Un estudio de la figura de un ricohombre en la Castilla del Cuatrocientos (CARLOS BARQUERO GOÑI)

517 BECEIRO PITA, Isabel (directora), La espiritualidad y la configuración de los reinos ibéricos (siglos XII-XV) (ENRIQUE Cantera Montenegro)

529 Galende Díaz, Juan Carlos, Ávila SeoAne, Nicolás, El rodado regio hispánico: León y Castilla antes de la unificación (1157-1230) (MAURICIO HERRERO JIMÉNEZ)

533 IrIJOA Cortés, Iago, GoICOLEA Julián, Francisco Javier, García FERNÁNDEZ, Ernesto (coords.), Mercaderes y financieros vascos y riojanos en Castilla y en Europa en el tránsito de la Edad Media a la Moderna (Ana MARÍA Rivera MEdina) 


\section{2 -}

\section{ESPACIO,}

\section{TIEMPO}

\section{Y FORMA}

UกED

SERIE III HISTORIA MEDIEVAL

REVISTA DE LA FACULTAD DE GEOGRAFÍA E HISTORIA

\section{Libros · Books}

537 LACARRA, José María, Alfonso el Batallador. Estudio preliminar de Fermín Miranda (PAULINA LóPEZ PITA)

541 Martín López, María Encarnación y CaVero Domínguez, Gregoria, Colección Documental del Monasterio de San Guillermo de Villabuena (1172-1527) (JOSÉ MIGUEL LóPEZ VILLALBA)

545 Martín Prieto, Pablo, Las Cruzadas (Margarita Cantera MONTENEGRO)

547 Rı, Alice, Legal Practice and the Written World in the Early Middle Ages. Frankish Formulae, c. 500-1000 (AlEjANDRO PABLO BAÑón PARDO)

551 RoYo PÉrez, Vicent, Les arrels històriques de la comarca dels Ports. Societat, poder i identitat en una terra de frontera durant la Baixa Edat Mitjana (JULIÁN DONADO VARA)

555 SANTIAgo Fernández, Javier de, Política monetariay moneda en el reinado de Carlos II (José Miguel López VILLALBA)

559 Santiago Fernández, Javier de y Francisco Olmos, José María. de, Corpus Inscriptionum Hispaniae Mediaevalium. Guadalajara (11121499) (José Miguel López VILLALBA)

563 Solórzano Telechea, Jesús A. y Sousa Melo, Arnaldo (eds.), ZALACAIN) Trabajar en la ciudad medieval europea (ROBERTO J. GONZÁLEZ

567 Solórzano Telechea, J.A., Haemers, J., Czaja, R. (eds.), Exclusión y disciplina social en la ciudad medieval europea (MARÍA ÁlvareZ FernánDEZ)

571 TRANChant, Mathias, Les ports maritimes de la France atlantiMARTÍN PÉREZ) que $\left(X l^{e}-X V^{e}\right.$ siècle). Volume I: Tableau géohistorique (FERNANDO 